\title{
Variação espacial e temporal nas assembléias de peixes de riachos na bacia do rio Guiraí, Alto Rio Paraná
}

\author{
Yzel Rondon Súarez ${ }^{1,2}$ \& Sidnei Eduardo Lima-Junior ${ }^{1}$ \\ ${ }^{1}$ Laboratório de Ecologia, Centro Integrado de Análise e Monitoramento Ambiental, \\ Universidade Estadual de Mato Grosso do Sul - UEMS \\ Rod. Dourados-Itahum, Km 12, CEP 79804-970, Dourados, MS, Brasil \\ ${ }^{2}$ Autor para correspondência: Yzel Rondon Súarez,e-mail: yzel@ uem.br
}

SÚAREZ, Y.R. \& LIMA-JÚNIOR, S.E. Spatial and temporal variation in stream fish assemblages of Guiraí River Basin, Upper Paraná Basin. Biota Neotrop., 9(1): http://www.biotaneotropica.org.br/v9n1/en/ abstract?article+bn01709012009.

\begin{abstract}
This paper aims to characterize the fish assemblages and to quantify the importance of spatial and temporal variations on the organization of stream fish assemblages of Guiraí River Basin, Upper Paraná River Basin. The samples were taken every two months in seven streams, from October 2006 to August 2007. To examine these data, we used analysis such as cluster, similarity, variance, canonical correspondence and regression tree. We collected 64 species and the spatial variations of the assemblages were more evident than the temporal ones. The most important variables in determining the occurrence of the species were altitude of the region, stream width and depth and water velocity. This result indicates there is an interaction of regional factors (altitude) with local ones (depth, velocity and width) to define the species composition of each stream. The turnover in species composition was significantly influenced by stream depth and altitude. The differentiation on richness and species composition between upper and lower sites should allow richness increment at regional level (hydrographic basin), decreasing the niches overlap and maintenance of sub-populations (for wide-distributed species) which should to resist more to the antropic action over the habitat structure.
\end{abstract}

Keywords: Mato Grosso do Sul State, species richness, species composition, fish assemblages, spatial variation, temporal variation.

SÚAREZ, Y.R. \& LIMA-JÚNIOR, S.E. Variação espacial e temporal nas assembléias de peixes de riachos na bacia do rio Guiraí, Alto Rio Paraná. Biota Neotrop., 9(1): http://www.biotaneotropica.org.br/v9n1/pt/ abstract?article+bn01709012009.

Resumo: O presente trabalho procura caracterizar as comunidades de peixes relacionando a variação espacial e temporal com a organização das comunidades de peixes em riachos da bacia do rio Guiraí, Alto Rio Paraná. As amostragens foram realizadas bimestralmente em sete riachos, entre outubro/2006 e agosto/2007 e, para a análise destes dados, utilizamos análises de agrupamento, de similaridade, de variância, de correspondência canônica e árvore de regressão. Foram coletadas 64 espécies de peixes e a variação espacial das comunidades estudadas se mostrou mais evidente que a variação temporal. As variáveis mais importantes na determinação da ocorrência das espécies foram a altitude do trecho amostrado, largura e profundidade do riacho e velocidade da água, o que indica que há interação de fatores em escala regional (altitude) com fatores locais (profundidade, velocidade e largura) na definição da composição de espécies em cada um dos riachos amostrados. O turnover na composição de espécies foi significativamente influenciado pela profundidade e altitude dos riachos. A diferenciação na riqueza e composição de espécies entre os trechos superiores e inferiores da bacia pode permitir o incremento da riqueza em nível regional (bacia hidrográfica) através da diminuição da sobreposição de nichos, permitindo a manutenção de subconjuntos populacionais (para as espécies de distribuição ampla) que podem resistir melhor às alterações antrópicas na estrutura dos habitats.

Palavras-Chave: Mato Grosso do Sul, riqueza de espécies, composição de espécies, assembléias de peixes, variação espacial, variação temporal. 


\section{Introdução}

As comunidades locais são influenciadas por um conjunto de fatores, que incluem características biogeográficas, bióticas e ambientais (Hoeinghaus et al. 2007), sendo que, de acordo com a escala analisada, um ou outro fator pode assumir maior importância (Jackson et al. 2001). A ictiofauna de riachos tem sido frequentemente descrita como resultado principalmente de restrições biogeográficas e hidrológicas (Poff 1997), combinadas com preferências ambientais similares das espécies de peixes, com pouca influência das interações biológicas (Peres-Neto 2004).

A ictiofauna neotropical é uma das mais diversificadas do mundo, com mais de $46 \%$ das 13.000 espécies de água doce registradas até então (Reis et al. 2003). Contudo, esta elevada diversidade ainda é pouco conhecida, com grandes áreas geográficas que representam lacunas no conhecimento da composição e ecologia da ictiofauna (Lévêque et al. 2008). A bacia do Alto Rio Paraná é uma das áreas com maior número de estudos ictiofaunísticos realizados, o que, contudo, não significa que esta seja bem conhecida. Em um recente estudo, Langeani et al. (2007) listam 310 espécies de peixes nesta região, além de pelo menos outras 50 espécies já identificadas, mas ainda não descritas, o que reforça a necessidade de estudos ictiofaunísticos nesta região, principalmente em áreas ainda pouco amostradas, fornecendo assim, ferramentas de grande importância para a conservação dos recursos aquáticos.

Os trabalhos já realizados sobre a organização da ictiofauna na bacia do Alto Rio Paraná, de modo geral, sugerem que as diferenças espaciais ao longo do gradiente longitudinal nos rios estão entre os principais determinantes da distribuição das espécies (Abes \& Agostinho 2001, Pavanelli \& Caramaschi 2003, Gerhard et al. 2004, Súarez \& Petrere Júnior 2007), sendo que a integridade da vegetação ciliar (Cetra \& Petrere Júnior 2006) e a qualidade da água também atuam de forma significativa sobre a distribuição das espécies (Ferreira \& Casatti 2006). Outros estudos têm sugerido que a sazonalidade atua como fator chave na organização das comunidades de peixes (Agostinho et al. 2004, Fialho et al. 2008). Pavanelli \& Caramaschi (2003) sugeriram que a variação temporal na composição da ictiofauna em riachos da região de Porto Rico (PR) foi maior em locais mais próximos à planície alagável do rio Paraná, indicando que a importância das migrações sazonais sobre as comunidades se altera de acordo com a posição na bacia hidrográfica.

Desta forma, no presente estudo foram caracterizadas as comunidades de peixes da bacia do rio Guiraí, Alto Paraná, por meio da análise da variação espacial e temporal na riqueza e composição de espécies, respondendo às seguintes questões: 1) Quais e quantas espécies de peixes ocorrem nos riachos amostrados da bacia do rio Guiraí? 2) Existe variação espacial e temporal na riqueza e composição de espécies de peixes nos riachos amostrados na bacia do rio Guiraí? e 3) Quais características fisiográficas e limnológicas dos riachos são mais importantes na determinação da diversidade e distribuição das espécies de peixes?

\section{Material e Métodos}

\section{Coleta de dados}

As amostragens foram realizadas bimestralmente em sete riachos (G1-G7) na bacia do rio Guiraí, Alto Rio Paraná (Figura 1), de outubro/2006 a agosto/2007. Os riachos foram selecionados de acordo com a posição na rede de drenagem e facilidade de deslocamento por terra. O ponto G3 é o que apresenta o menor volume, com menor largura $(1,2 \mathrm{~m})$ e profundidade $(26 \mathrm{~cm})$, ainda que seja um riacho

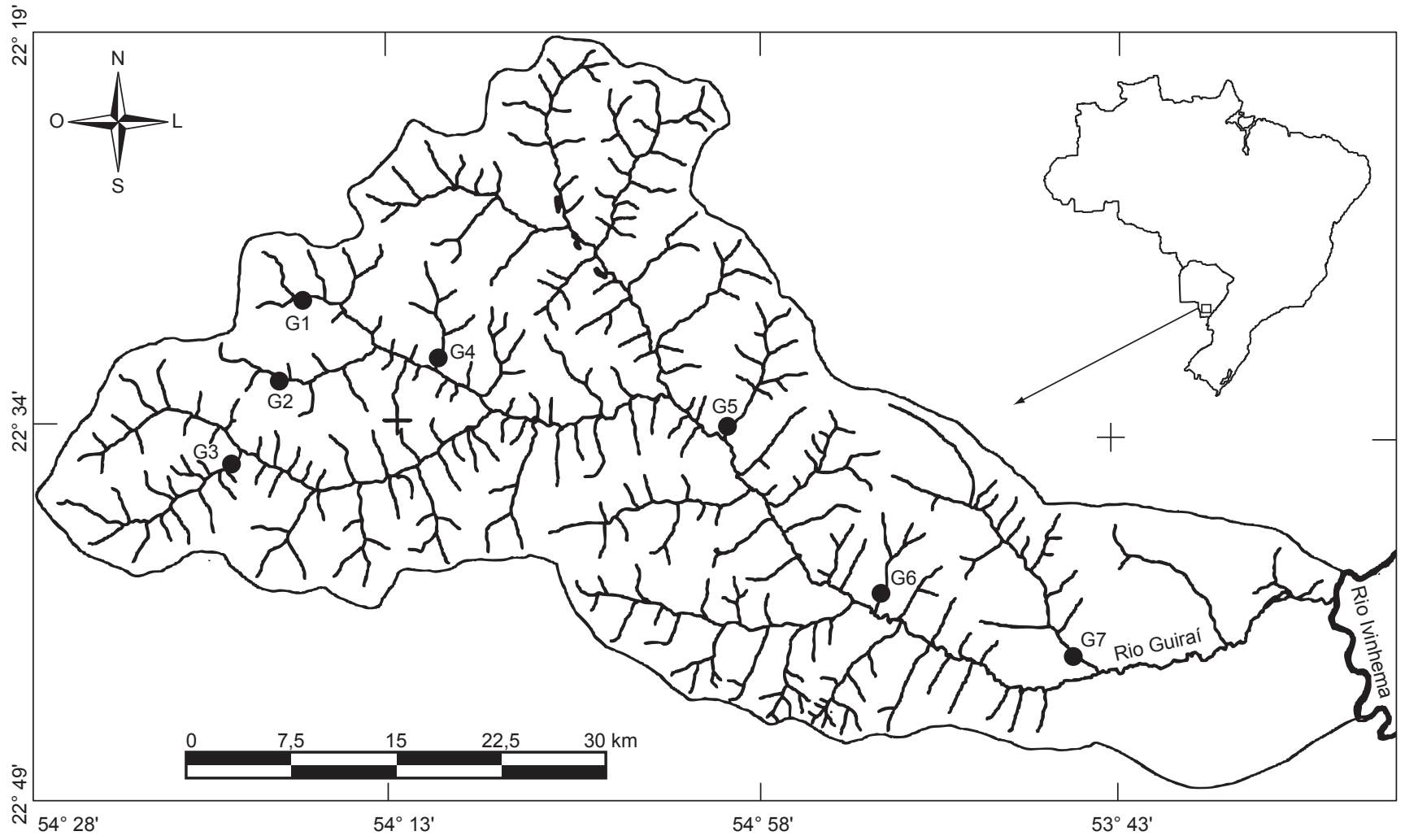

Figura 1. Mapa da bacia do rio Guiraí, Alto Rio Paraná, com os locais amostrados entre outubro/2006 e agosto/2007, Mato Grosso do Sul State.

Figure 1. Map of the Guiraí river basin, Upper Paraná basin with sampled streams from October/2006 to August/2007. 
de $3^{\mathrm{a}}$ ordem, enquanto o ponto G7 é o mais volumoso, com $6,5 \mathrm{~m}$ de largura e $126 \mathrm{~cm}$ de profundidade média (Tabela 1). O local com maior velocidade média da correnteza foi o G6, enquanto os pontos G1 e G7 foram os que apresentaram menor velocidade da correnteza, sendo que o G7 apresenta uma pequena área alagável em suas margens, com predomínio de Eichhornia azurea e Echinodorus sp. e com grande quantidade de matéria orgânica no sedimento.

As amostragens foram realizadas utilizando-se cinco redes de espera (1,5 × $10 \mathrm{~m}$, malhas de 1,5 a $5 \mathrm{~cm}$ entre nós adjacentes), redes de arrasto $(1,5 \times 5$ e $1,5 \times 10 \mathrm{~m}$, malha de $5 \mathrm{~mm})$ e telas de isca $(80 \times 120 \mathrm{~cm}$, malha de aproximadamente $2 \mathrm{~mm})$ em um trecho de aproximadamente $100 \mathrm{~m}$ de extensão. Em cada riacho foram aplicadas as combinações de métodos de amostragem de acordo com as características locais. Nos riachos mais estreitos e rasos foi utilizada basicamente a tela de isca e, quando possível, redes de arrasto. Nos locais com maior volume foram armadas redes de espera no período da tarde e recolhidas na manhã seguinte, ficando armadas entre $16 \mathrm{e}$ 18 horas; nestes locais também foram utilizadas as telas de isca, visando amostrar espécies de pequeno porte não capturáveis com redes de espera. O número de lances de telas de isca não foi padronizado entre os locais, sendo proporcional ao volume do riacho. Por este motivo, todas as análises foram realizadas com dados de presença/ausência, uma vez que as diferenças nos métodos de amostragem e no esforço amostral impede a comparação na abundância das espécies.

Em campo foram obtidas as seguintes características ambientais: largura e profundidade média do riacho, velocidade média da água, temperatura da água, $\mathrm{pH}$, condutividade elétrica, turbidez da água e altitude $(\mathrm{m})$. Os peixes coletados foram fixados em formol a $10 \%$ por pelo menos 48 horas e em laboratório preservados em álcool 70\% para posterior identificação. Os peixes foram identificados utilizando-se como base a chave para identificação de peixes do Pantanal (Britski et al., 1999), bem como o trabalho de Graça \& Pavanelli (2007) e chaves específicas para cada grupo taxonômico.

\section{Análise dos dados}

A riqueza total nos riachos amostrados foi estimada através do método bootstrap (Efron 1979), bem como seu desvio padrão, por meio do software EstimateS (Colwell 1997), com 50 permutações.

Uma análise de agrupamento foi realizada com o objetivo de permitir a visualização dos grupos naturais de amostras, de acordo com a ocorrência das espécies de peixes (coeficiente de Jaccard), utilizando o método de ligação UPGMA. O coeficiente de correlação cofenética foi utilizado como indicativo de fidelidade do dendrograma gerado à matriz inicial de similaridade, sendo que o valor de 0,75 foi definido como mínimo para que o dendrograma fosse considerado fiel à matriz de similaridade (Jongman et al. 1995).

Uma análise de similaridade (ANOSIM) foi realizada para verificar a existência de diferença espacial (entre locais) e temporal (estações seca e chuvosa) na composição de espécies de peixes nos riachos amostrados (Clarke 1993). Os meses de outubro, dezembro e fevereiro foram considerados como pertencentes à estação chuvosa e os meses de abril, junho e agosto como pertencentes à estação chuvosa. Esta análise foi realizada utilizando-se a rotina ANOSIM do software VEGAN (Oksanen et al. 2006), disponível na plataforma R (R Development Core Team 2005).

A importância da variação espacial e temporal sobre a riqueza de espécies nas comunidades analisadas foi verificada através de uma análise de variância tendo como variável resposta a riqueza de espécies e, como variáveis explanatórias, o local amostrado (riacho) a estação amostrada (chuvosa e seca). A comparação a posteriori dos grupos foi realizada através do teste de Tukey.

A influência das características de cada riacho sobre o turnover na composição de espécies ao longo do período amostrado foi analisada através de análises de correlação de Pearson entre os valores médios das características físicas e químicas dos riachos e a altitude (variáveis explanatórias) e a taxa de turnover temporal na composição de espécies (variável resposta). A taxa de turnover na composição de espécies foi definida como: riqueza total menos riqueza média $(\beta=\gamma-\alpha)$, de acordo com a metodologia proposta por MacArthur et al. (1966). Desta forma, locais que apresentam elevada riqueza total (acumulada), mas baixo número médio de espécies por coleta apresentam alta taxa de alteração temporal na composição de espécies.

A quantificação da importância das características fisiográficas e limnológicas sobre a riqueza de espécies foi obtida através de uma análise de árvore de regressão, onde a riqueza de espécies em cada amostra foi utilizada como variável resposta e as características ambientais como variáveis explanatórias. A análise de árvore de regressão é um método de particionamento da variabilidade na variável resposta, onde as observações são divididas em grupos mutuamente exclusivos, sendo estes grupos os mais homogêneos possíveis (De'Ath \& Fabricius 2000). Entre as vantagens deste método, estão a simplicidade na interpretação gráfica dos resultados e a ausência de necessidade de transformações de dados e o fato dos resultados serem mais parcimoniosos (Turgeon \& Rodriguez 2005), sendo que ainda consegue captar de forma eficiente a importância de variáveis explanatórias que apresentem influência linear ou não linear sobre a variável resposta.

Tabela 1. Valores médios e desvio padrão para as variáveis ambientais obtidas nos locais amostrados na bacia do rio Guiraí, Alto Rio Paraná, entre outubro/2006 e agosto/2007.

Table 1. Mean values and standard deviation for environmental descriptors obtained in sampled streams in Guiraí River basin, Upper Paraná basin, from October/2006 to August/2007.

\begin{tabular}{|c|c|c|c|c|c|c|c|}
\hline Variáveis/Locais & G1 & G2 & G3 & G4 & G5 & G6 & G7 \\
\hline Ordem & $2^{a}$ & $2^{\mathrm{a}}$ & $3^{\mathrm{a}}$ & $2^{a}$ & $3^{\mathrm{a}}$ & $2^{a}$ & $3^{\mathrm{a}}$ \\
\hline Largura (m) & $1,8 \pm 0,1$ & $5,2 \pm 0,5$ & $1,2 \pm 0,1$ & $4,4 \pm 0,2$ & $4,5 \pm 0,3$ & $3,4 \pm 0,2$ & $6,5 \pm 0,4$ \\
\hline Profundidade (cm) & $65 \pm 7,3$ & $73 \pm 15,9$ & $26 \pm 5,7$ & $51 \pm 16,5$ & $51 \pm 5,0$ & $59 \pm 7,3$ & $126 \pm 5,3$ \\
\hline Velocidade (m/s) & $0,4 \pm 0,2$ & $0,6 \pm 0,15$ & $0,8 \pm 0,3$ & $0,7 \pm 0,3$ & $0,7 \pm 0,2$ & $0,9 \pm 1,0$ & $0,3 \pm 0,02$ \\
\hline Altitude (m) & 368 & 332 & 353 & 308 & 304 & 271 & 244 \\
\hline $\mathrm{pH}$ & $6,7 \pm 0,8$ & $6,9 \pm 0,4$ & $6,7 \pm 0,7$ & $6,8 \pm 0,7$ & $5,5 \pm 1,3$ & $6,7 \pm 0,5$ & $6,6 \pm 0,6$ \\
\hline Condutividade $(\mu \mathrm{S} / \mathrm{cm})$ & $234,9 \pm 534$ & $401 \pm 938$ & $231 \pm 533$ & $204,7 \pm 461$ & $599,7 \pm 1376$ & $291 \pm 668$ & $238,5 \pm 544$ \\
\hline Turbidez (NTU) & $14,4 \pm 8$ & $24,5 \pm 23,1$ & $7,5 \pm 3,1$ & $13,1 \pm 1,5$ & $42,0 \pm 38$ & $46,9 \pm 86,4$ & $19,6 \pm 10,6$ \\
\hline Temperatura $\left({ }^{\circ} \mathrm{C}\right)$ & $22,9 \pm 2,5$ & $22,4 \pm 2,0$ & $22,8 \pm 2,4$ & $24,6 \pm 2,8$ & $23,8 \pm 1,3$ & $24,3 \pm 2,5$ & $23,8 \pm 2,3$ \\
\hline
\end{tabular}


Após a padronização das variáveis ambientais, a sua importância para a ocorrência das principais espécies de peixes (ocorrendo em pelo menos 4 amostras) foi quantificada através de uma análise de correspondência canônica (Ter Braak 1986). Esta análise foi realizada utilizando-se o software R (R Development Core Team 2005), utilizando-se a função CCA no software VEGAN. A significância das variáveis ambientais foi obtida através da rotina ENVFIT que obtêm uma medida de $\mathrm{r}^{2}$ para cada variável e através de um procedimento de aleatorização (999 permutações), define a significância para os eixos em conjunto.

\section{Resultados}

Coletamos 64 espécies de peixes, com predominância das ordens Characiformes (31 espécies) e Siluriformes (20 espécies). A espécie mais comum nos riachos amostrados foi Bryconamericus stramineus Eigenmann, 1908, que ocorreu em 76,2\% das amostras, seguida por Hypostomus ancistroides (Ihering, 1911), que ocorreu em 64,3\% das amostras (Tabela 2). Por outro lado, 14 espécies $(21,9 \%)$ ocorreram em apenas uma amostra. A estimativa de riqueza de espécies para os riachos amostrados é de 71 espécies, indicando que $90,1 \%$ das espécies existentes nestes riachos foram coletadas (Figura 2).

Tabela 2. Lista de espécies de peixes coletadas nos riachos da bacia do rio Guiraí, Alto Rio Paraná, Mato Grosso do Sul.

Table 2. List of sampled fish species in streams of Guiraí River basin, Upper Paraná basin, Mato Grosso do Sul State.

\begin{tabular}{|c|c|c|c|c|c|c|c|}
\hline Espécie/Ordem/Família & G1 & G2 & G3 & G4 & G5 & G6 & G7 \\
\hline \multicolumn{8}{|l|}{ Characiformes } \\
\hline \multicolumn{8}{|l|}{ ANOSTOMIDAE } \\
\hline Leporinus friderici (Bloch, 1794) & - & - & - & - & - & $\mathrm{x}$ & $\mathrm{x}$ \\
\hline Leporinus lacustris Campos, 1945 & - & - & - & - & - & - & $\mathrm{x}$ \\
\hline Leporinus obtusidens (Valenciennes, 1836) & - & - & - & $\mathrm{x}$ & - & - & - \\
\hline \multicolumn{8}{|l|}{ CHARACIDAE } \\
\hline Acestrorhynchus lacustris (Lütken, 1875) & - & - & - & - & - & - & $\mathrm{x}$ \\
\hline Aphyocharax dentatus Eigenmann \& Kennedy, 1903 & - & - & - & - & - & - & $\mathrm{x}$ \\
\hline Astyanax altiparanae Garutti \& Britski, 2000 & $\mathrm{x}$ & $\mathrm{x}$ & $\mathrm{x}$ & $\mathrm{x}$ & - & $\mathrm{x}$ & $\mathrm{x}$ \\
\hline Astyanax fasciatus (Cuvier, 1819) & $\mathrm{x}$ & $\mathrm{x}$ & - & $\mathrm{x}$ & $\mathrm{x}$ & - & - \\
\hline Astyanax paranae Eigenmann, 1914 & $\mathrm{x}$ & $\mathrm{x}$ & $\mathrm{x}$ & $\mathrm{x}$ & $\mathrm{x}$ & $\mathrm{x}$ & $\mathrm{x}$ \\
\hline Bryconamericus stramineus Eigenmann, 1908 & $\mathrm{x}$ & $\mathrm{x}$ & $\mathrm{x}$ & $\mathrm{x}$ & $\mathrm{x}$ & $\mathrm{x}$ & $\mathrm{x}$ \\
\hline Hyphessobrycon eques (Steindachner, 1882) & - & - & - & - & - & - & $\mathrm{x}$ \\
\hline Hemigrammus marginatus Ellis, 1911 & - & - & - & - & - & $\mathrm{x}$ & $\mathrm{x}$ \\
\hline Metynnis lippincottianus (Cope, 1870) & - & - & - & - & - & - & $\mathrm{x}$ \\
\hline Moenkhausia sanctaefilomenae (Steindachner, 1907) & - & - & - & - & - & $\mathrm{x}$ & $\mathrm{x}$ \\
\hline Oligosarcus pintoi Campos, 1945 & $\mathrm{x}$ & - & $\mathrm{x}$ & - & $\mathrm{x}$ & - & $\mathrm{x}$ \\
\hline Piabina argentea Reinhardt, 1866 & - & $\mathrm{x}$ & - & - & $\mathrm{x}$ & - & $\mathrm{x}$ \\
\hline Salminus hilarii Valenciennes, 1850 & - & - & - & $\mathrm{x}$ & $\mathrm{x}$ & - & - \\
\hline Serrapinnus notomelas (Eigenmann, 1915) & - & - & $\mathrm{x}$ & $\mathrm{x}$ & $\mathrm{x}$ & $\mathrm{x}$ & $\mathrm{x}$ \\
\hline Serrapinnus sp. & - & - & - & - & - & - & $\mathrm{x}$ \\
\hline Serrasalmus marginatus Valenciennes, 1847 & - & - & - & - & - & - & $\mathrm{x}$ \\
\hline Psellogrammus kennedyi (Eigenmann, 1903) & - & - & - & - & - & - & $\mathrm{x}$ \\
\hline \multicolumn{8}{|l|}{ CURIMATIDAE } \\
\hline Cyphocharax modestus (Fernández-Yépez, 1948) & - & - & - & - & - & - & $\mathrm{x}$ \\
\hline Steindachnerina brevipinna (Eigenmann \& Eigenmann, 1889) & - & - & - & - & - & - & $\mathrm{x}$ \\
\hline \multicolumn{8}{|l|}{ CRENUCHIDAE } \\
\hline Characidium gomesi Travassos, 1956 & - & - & - & $\mathrm{x}$ & - & - & - \\
\hline Characidium cf. lagosantense Travassos, 1947 & - & - & - & $\mathrm{x}$ & - & - & $\mathrm{x}$ \\
\hline Characidium zebra Eigenmann, 1909 & $\mathrm{x}$ & $\mathrm{x}$ & - & $\mathrm{x}$ & $\mathrm{x}$ & $\mathrm{x}$ & - \\
\hline Characidium sp. & - & $\mathrm{x}$ & - & $\mathrm{x}$ & - & - & - \\
\hline \multicolumn{8}{|l|}{ ERYTHRINIDAE } \\
\hline Hoplias malabaricus (Bloch, 1794) & $\mathrm{x}$ & - & $\mathrm{x}$ & - & $\mathrm{x}$ & - & $\mathrm{x}$ \\
\hline \multicolumn{8}{|l|}{ LEBIASINIDAE } \\
\hline Pyrhulina australis Eigenmann \& Kennedy, 1903 & $\mathrm{x}$ & - & - & - & - & - & $\mathrm{x}$ \\
\hline \multicolumn{8}{|l|}{ PARODONTIDAE } \\
\hline Apareiodon ibitiensis Amaral Campos, 1944 & - & - & - & $\mathrm{x}$ & $\mathrm{x}$ & - & - \\
\hline Parodon nasus Kner, 1859 & - & - & - & $\mathrm{x}$ & - & - & - \\
\hline \multicolumn{8}{|l|}{ PROCHILODONTIDAE } \\
\hline Prochilodus lineatus (Valenciennes, 1837) & - & - & - & - & - & - & $\mathrm{x}$ \\
\hline \multicolumn{8}{|l|}{ Siluriformes } \\
\hline \multicolumn{8}{|l|}{ AUCHENIPTERIDAE } \\
\hline Tatia neivai (Ihering, 1930) & - & - & - & - & - & $\mathrm{x}$ & $\mathrm{x}$ \\
\hline
\end{tabular}


Tabela 2. Continuação...

\begin{tabular}{|c|c|c|c|c|c|c|c|}
\hline Espécie/Ordem/Família & G1 & G2 & G3 & G4 & G5 & G6 & G7 \\
\hline Trachelyopterus sp. & - & - & - & - & - & - & $\mathrm{x}$ \\
\hline \multicolumn{8}{|l|}{ ASPREDINIDAE } \\
\hline Bunocephalus larai Ihering, 1930 & - & - & - & - & - & - & $\mathrm{x}$ \\
\hline \multicolumn{8}{|l|}{ CALLICHTHYIDAE } \\
\hline Corydoras aeneus (Gill, 1858) & - & - & - & $\mathrm{x}$ & $\mathrm{x}$ & $\mathrm{x}$ & $\mathrm{x}$ \\
\hline Hoplosternum litoralle (Hancock, 1828) & - & - & - & - & - & - & $\mathrm{x}$ \\
\hline \multicolumn{8}{|l|}{ CETOPSIDAE } \\
\hline Cetopsis gobioides (Kner, 1858) & - & - & - & - & - & $\mathrm{x}$ & - \\
\hline \multicolumn{8}{|l|}{ LORICARIIDAE } \\
\hline Farlowella sp. & - & - & - & - & - & $\mathrm{x}$ & - \\
\hline Hisonotus sp. & - & $\mathrm{x}$ & $\mathrm{x}$ & $\mathrm{x}$ & - & $\mathrm{x}$ & $\mathrm{x}$ \\
\hline Hypostomus ancistroides (Ihering, 1911) & $\mathrm{x}$ & $\mathrm{x}$ & $\mathrm{x}$ & $\mathrm{x}$ & $\mathrm{x}$ & $\mathrm{x}$ & $\mathrm{x}$ \\
\hline Hypostomus nigromaculatus (Schubart, 1964) & - & - & - & $\mathrm{x}$ & $\mathrm{x}$ & - & - \\
\hline Hypostomus strigaticeps (Regan, 1908) & - & $\mathrm{x}$ & - & $\mathrm{x}$ & - & - & - \\
\hline Hypostomus sp. & - & $\mathrm{x}$ & - & $\mathrm{x}$ & $\mathrm{x}$ & $\mathrm{x}$ & - \\
\hline Loricariichthys platymetopon Isbrücker \& Nijssen, 1979 & - & - & - & - & - & $\mathrm{x}$ & $\mathrm{x}$ \\
\hline \multicolumn{8}{|l|}{ Rineloricaria lanceolata (Günther, 1868) } \\
\hline HEPTAPTERIDAE & $\mathrm{x}$ & $\mathrm{x}$ & - & $\mathrm{x}$ & $\mathrm{x}$ & $\mathrm{x}$ & - \\
\hline \multicolumn{8}{|l|}{ Cetopsorhamdia iheringi Schubart \& Gomes, 1959} \\
\hline Imparfinis mirini Haseman, 1911 & - & - & - & - & $\mathrm{x}$ & - & - \\
\hline Phenacorhamdia tenebrosa (Schubart, 1964) & $\mathrm{x}$ & - & $\mathrm{x}$ & - & $\mathrm{x}$ & $\mathrm{x}$ & - \\
\hline Rhamdia quelen (Quoy \& Gaimard, 1824) & $\mathrm{x}$ & - & - & - & - & - & - \\
\hline PIMELODIDAE & $\mathrm{x}$ & - & $\mathrm{x}$ & - & - & $\mathrm{x}$ & - \\
\hline Pseudoplatystoma corruscans (Spix \& Agassiz, 1829) & - & - & - & - & - & - & $\mathrm{x}$ \\
\hline \multicolumn{8}{|l|}{ PSEUDOPIMELODIDAE } \\
\hline Pseudopimelodus mangurus (Valenciennes, 1835) & - & - & - & - & - & - & $\mathrm{x}$ \\
\hline \multicolumn{8}{|l|}{ Gymnotiformes } \\
\hline \multicolumn{8}{|l|}{ APTERONOTIDAE } \\
\hline Apteronotus albifrons (Linnaeus, 1766) & - & - & - & - & - & $\mathrm{x}$ & - \\
\hline \multicolumn{8}{|l|}{ GYMNOTIDAE } \\
\hline Gymnotus sp. & $\mathrm{x}$ & - & - & - & - & - & $\mathrm{x}$ \\
\hline \multicolumn{8}{|l|}{ HYPOPOMIDAE } \\
\hline Brachyhypopomus pinnicaudatus (Hopkins et al, 1990) & - & - & - & - & - & - & $\mathrm{x}$ \\
\hline \multicolumn{8}{|l|}{ RHAMPHICHTHYIDAE } \\
\hline Gymnorhamphichthys hypostomus Ellis, 1912 & - & - & - & - & - & $\mathrm{x}$ & - \\
\hline \multicolumn{8}{|l|}{ STERNOPYGIDAE } \\
\hline Eigenmannia trilineata Lopez \& Castello, 1966 & - & - & - & - & - & $\mathrm{x}$ & $\mathrm{x}$ \\
\hline Eigenmannia virescens (Valenciennes, 1836) & - & - & - & - & - & - & $\mathrm{x}$ \\
\hline Sternopygus macrurus (Schneider, 1801) & - & - & - & - & - & - & $\mathrm{x}$ \\
\hline \multicolumn{8}{|l|}{ Perciformes } \\
\hline \multicolumn{8}{|l|}{ CICHLIDAE } \\
\hline Crenicichla britskii Kullander, 1982 & - & $\mathrm{x}$ & - & $\mathrm{x}$ & $\mathrm{x}$ & $\mathrm{x}$ & $\mathrm{x}$ \\
\hline Cichlasoma paranaense Kullander, 1983 & $\mathrm{x}$ & - & $\mathrm{x}$ & - & - & - & $\mathrm{x}$ \\
\hline Tilapia rendalli (Boulenger, 1897) & - & - & - & $\mathrm{x}$ & - & - & - \\
\hline \multicolumn{8}{|l|}{ Cyprinodontiformes } \\
\hline \multicolumn{8}{|l|}{ POECILIIDAE } \\
\hline Phallocerus harpagos Lucinda, 2008 & - & $\mathrm{x}$ & $\mathrm{x}$ & $\mathrm{x}$ & $\mathrm{x}$ & $\mathrm{x}$ & $\mathrm{x}$ \\
\hline \multicolumn{8}{|l|}{ RIVULIDAE } \\
\hline Rivulus pictus Costa, 1989 & - & - & $\mathrm{x}$ & - & - & - & - \\
\hline \multicolumn{8}{|l|}{ Synbranchiformes } \\
\hline SYNBRANCHIDAE & & & & & & & \\
\hline Synbranchus marmoratus Bloch, 1795 & - & - & - & - & $\mathrm{x}$ & - & - \\
\hline
\end{tabular}




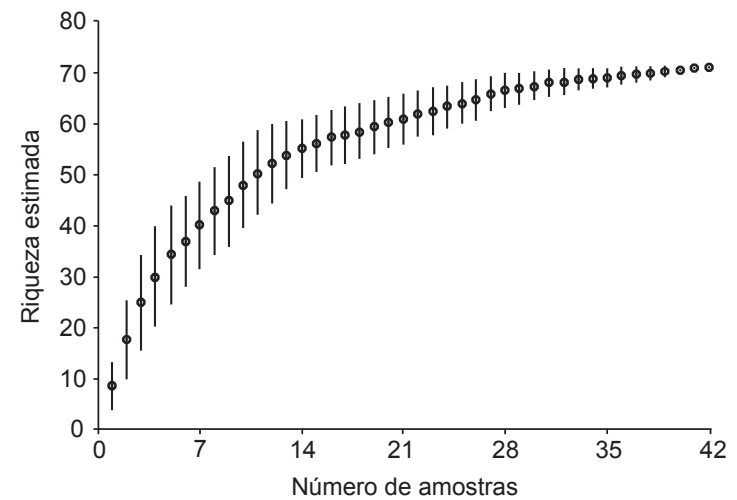

Figura 2. Estimativa bootstrap de riqueza de espécies e desvio padrão para as comunidades de peixes de riachos da bacia do rio Guiraí, Alto Rio Paraná, Mato Grosso do Sul.

Figure 2. Bootstrap estimative of species richness and standard deviation for stream fish communities in Guiraí River basin, Upper Paraná basin, Mato Grosso do Sul State.
O ponto com maior número de espécies foi o G7, com 41 espécies, seguido pelo ponto G6, com 25 espécies. Dezenove espécies, representando $29,7 \%$ da riqueza total, ocorreram exclusivamente no G7, entre elas, várias de grande porte e migradoras (p. ex.: P. corruscans, $P$. lineatus e $L$. friderici), sendo que, nas amostragens do período chuvoso, foi possível verificar que vários exemplares encontravam-se em avançado estágio de maturação gonadal.

Através da análise de agrupamento, constatamos clara diferenciação entre locais na composição de espécies, com pouca influência sazonal na ocorrência das espécies, onde os pontos localizados nos trechos de cabeceira (G1 a G3) e mesmo aqueles localizados em porções intermediárias da bacia (G4 a G6) apresentam baixa similaridade com os trechos finais da bacia (G7), com valores de aproximadamente $10 \%$ de similaridade (Figura 3). Esta diferença também foi constatada pela análise de similaridade (ANOSIM), em que se constata diferença entre os locais ( $\mathrm{r}=0,81 ; \mathrm{P}<0,001)$, mas não se encontra diferença temporal na composição de espécies $(\mathrm{r}=0,05 ; \mathrm{P}=0,074)$.

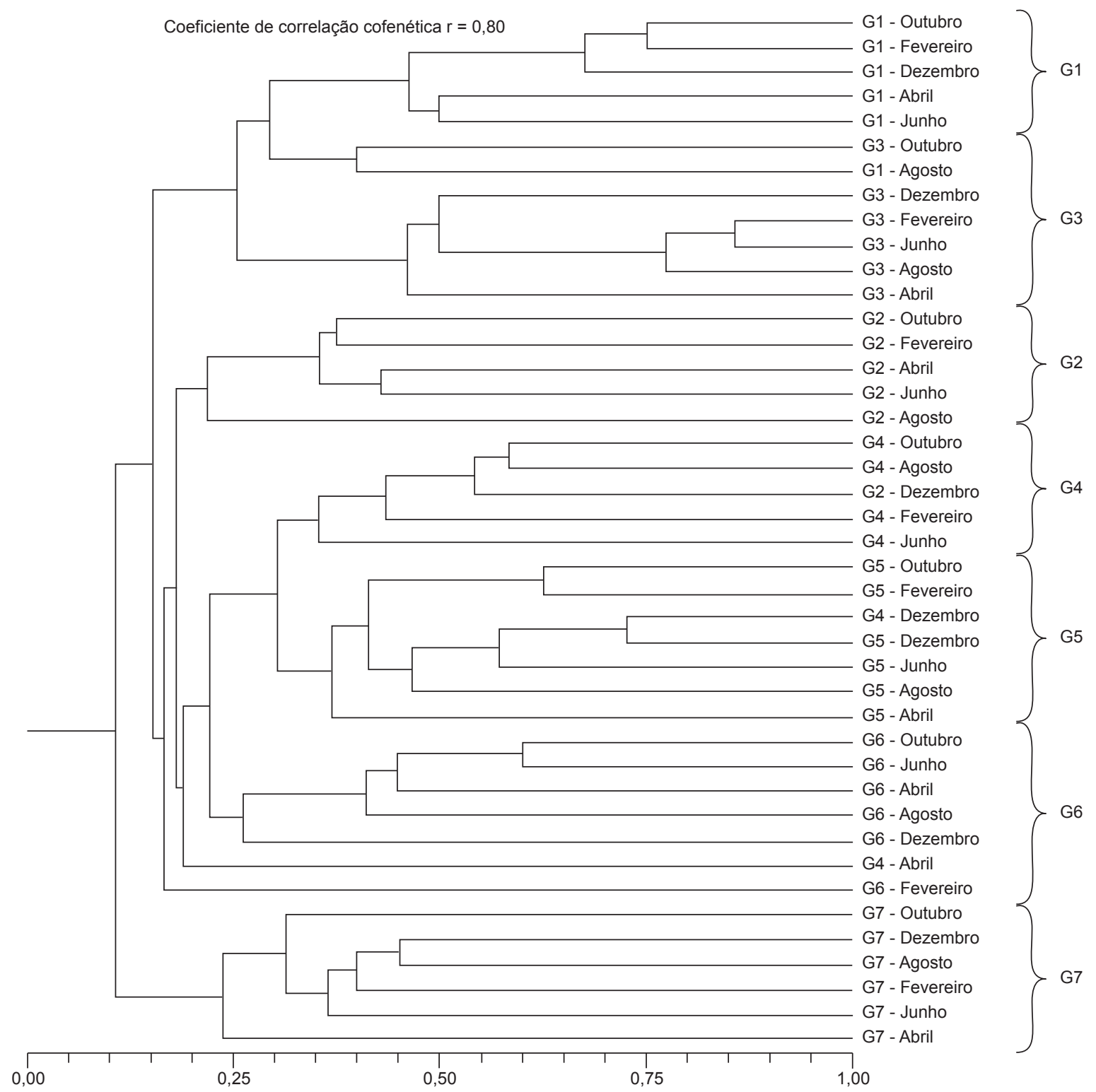

Figura 3. Dendrograma de similaridade entre para as comunidades de peixes em riachos da bacia do rio Guiraí, Alto Rio Paraná, Mato Grosso do Sul.

Figure 3. Similarity dendrogram among stream fish communities for Guiraí River basin, Upper Paraná basin, Mato Grosso do Sul State. 
A variação espacial (entre riachos) explicou significativamente $68,9 \%$ da variação na riqueza de espécies $\left(\mathrm{r}^{2}=0,689 ; \mathrm{F}_{6,35}=12,90\right.$; $\mathrm{P}<0,000)$. Em contraste, a variação temporal não é significativa, explicando apenas 3,3\% da variação na riqueza de espécies $\left(r^{2}=0,033\right.$; $\left.\mathrm{F}_{1,40}=1,36 ; \mathrm{P}=0,251\right)$. A interação entre as estações e os riachos não mostrou influência significativa sobre a riqueza de espécies $\left(r^{2}=0,033 ; F_{1,40}=1,38 ; P=0,246\right)$. Desta forma, o local G7 apresenta riqueza de espécies significativamente maior que os demais locais amostrados, mas não existe diferença na riqueza média entre os períodos seco e chuvoso (Figura 4) e a despeito de alguns locais (G2, G4 e G6) apresentarem maior riqueza no período chuvoso, a grande sobreposição nos intervalos de confiança não permite que as estações sejam consideradas significativamente diferentes.

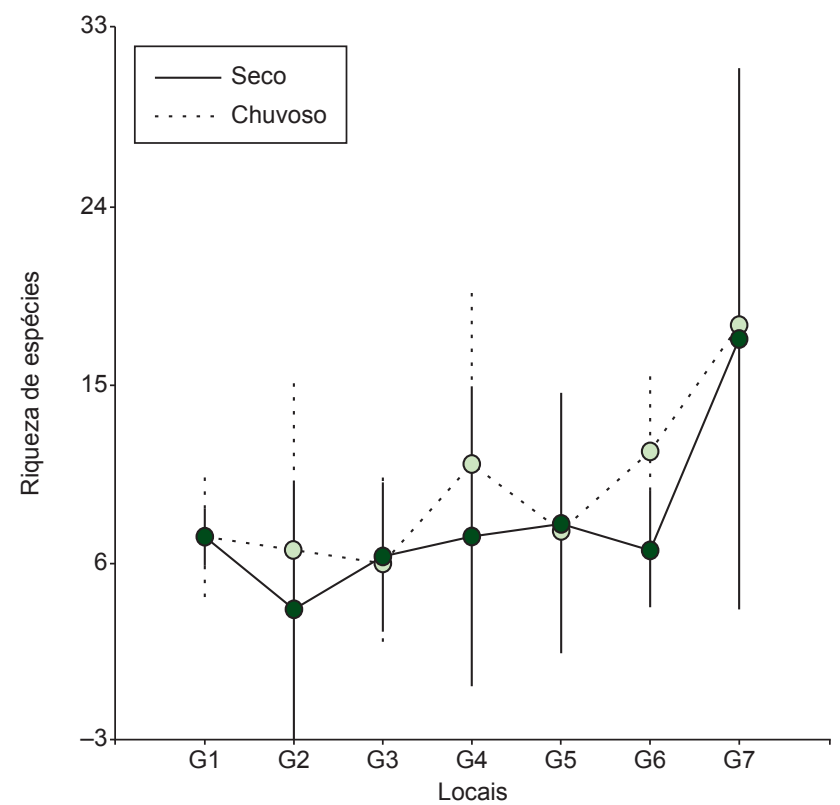

Figura 4. Riqueza média e intervalo de confiança para locais e períodos (seco e chuvoso) para as comunidades de peixes de riachos da bacia do rio Guiraí, Alto Rio Paraná, Mato Grosso do Sul.

Figure 4. Mean richness and confidence interval for sites and seasons (dry and rainy) for stream fish communities for Guiraí River basin, Upper Paraná basin, Mato Grosso do Sul State.
A análise da variação na taxa de alteração na composição de espécies (turnover) revelou que os locais amostrados na porção inferior da bacia hidrográfica apresentam maior turnover na composição de espécies, sendo que apenas a profundidade dos riachos $(\mathrm{r}=0,767$; $\mathrm{P}=0,044)$ e a altitude $(\mathrm{r}=-0,955 ; \mathrm{P}=0,001)$ influenciaram significativamente o turnover na composição de espécies. Apesar de não significativa, a largura do riacho $(\mathrm{r}=0,738 ; \mathrm{P}=0,058)$ é uma variável que deve ser levada em consideração, uma vez que o baixo número de observações (riachos amostrados) foi o responsável pela não significância desta correlação (Figura 5).

Através da análise de árvore de regressão, constatamos que 67,4\% da variação na riqueza de espécies pode ser explicada pela altitude e velocidade da água, sendo que locais com altitude menor que $271 \mathrm{~m}$ apresentam em média 17,67 espécies. Por outro lado, os pontos de maiores altitudes, mas que apresentam velocidade da correnteza maior que $0,93 \mathrm{~m} / \mathrm{s}$, apresentam em média 10,8 espécies de peixes, enquanto aqueles riachos que apresentam menor velocidade da correnteza apresentam em média 6,94 espécies (Figura 6).

O resultado da análise de correspondência canônica permitiu explicar $23,3 \%$ da variação na composição de espécies, sendo que o

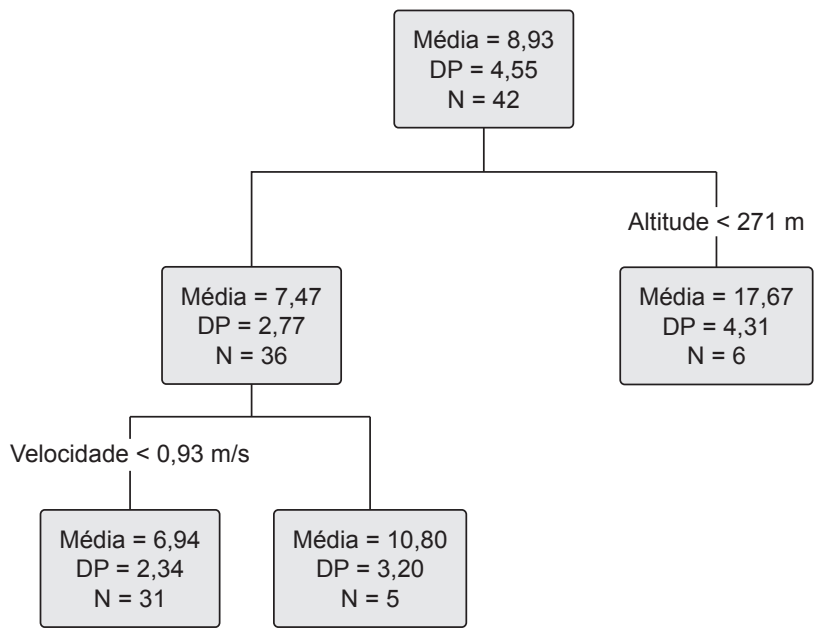

Figura 6. Fluxograma da árvore de regressão da riqueza de espécies de peixes nos riachos amostrados na bacia do rio Guiraí, Alto Rio Paraná.

Figure 6. Regression tree fluxogram for fish species richness in sampled streams in Guiraí River basin, Upper Paraná basin.
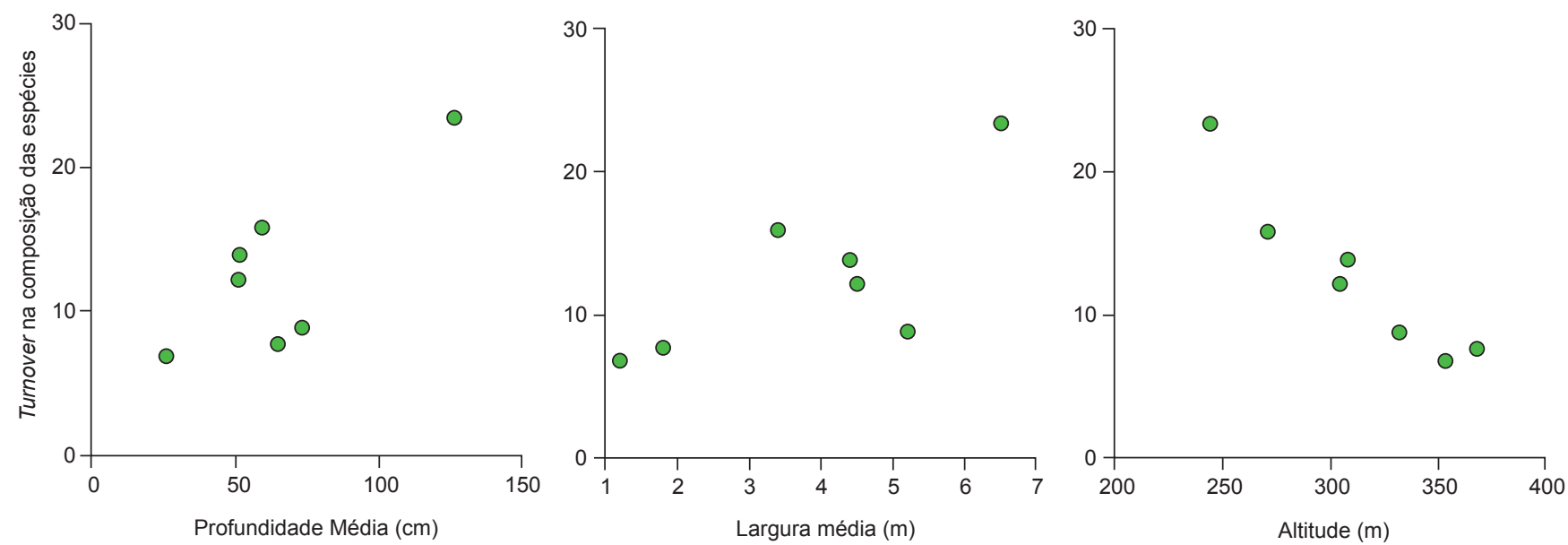

Figura 5. Influência das características ambientais sobre o turnover na composição de espécies de peixes nos riachos da bacia do rio Guiraí, Alto Rio Paraná.

Figure 5. Influence of environmental characteristics on turnover in fish species composition in streams of the Guiraí river basin, Upper Paraná River. 
primeiro eixo explicou $12,1 \%$, enquanto o eixo 2 explicou $11,2 \%$ da variação na composição de espécies. As variáveis mais importantes na determinação da ocorrência das espécies de peixes foram a altitude, largura, profundidade e velocidade da água no trecho amostrado (Tabela 3). Desta forma constata-se que $H$. eques, $H$. marginatus, C. lagosantense, E. trilineata, entre outras, tiveram sua ocorrência positivamente correlacionadas com a largura e profundidade dos riachos. Por outro lado, espécies como $P$. argentea, $H$. strigaticeps, $R$. lanceolata, B. stramineus, A. paranae, A. fasciatus ocorreram predominantemente em locais localizados a maiores altitudes e com maior velocidade da correnteza (Figura 7).

\section{Discussão}

A riqueza de espécies encontrada (64) pode ser considerada elevada, uma vez que outros estudos realizados na bacia do alto rio Paraná têm encontrado riqueza similar, coletados em um maior número de locais, mas sem repetição ao longo do tempo, como para os riachos da bacia do rio Paranapanema (SP) onde Castro et al. (2003) coletaram em 17 trechos de riachos e encontraram 54 espécies. Por outro lado, no rio Grande (SP), Castro et al. (2004) analisaram 18 locais e encontraram 64 espécies. Súarez \& Petrere Júnior (2005), analisando as comunidades de peixes de riachos na bacia do rio Iguatemi (MS), encontraram 24 espécies de peixes em 15 amostragens (14 riachos). Súarez (2008) analisando as comunidades de peixes em sete trechos de riachos da porção inferior da bacia do rio Ivinhema encontraram 46 espécies de peixes. A riqueza de espécies encontrada no presente trabalho foi maior em comparação aos resultados dos estudos acima citados, sendo que mais de $90 \%$ do número estimado de espécies foi coletado.

Segundo Matthews (1998), as comunidades locais de peixes de riachos apresentam normalmente a riqueza acumulada de cerca de 20 espécies, com riqueza média de aproximadamente 8 espécies, com raras exceções em que podem apresentar riqueza acumulada de mais de 100 espécies; resultado também constatado nos riachos estudados na mata atlântica (Gerhard et al., 2004), na bacia do alto rio Paraná (Castro et al., 2003, 2004, 2005) e no presente estudo. Desta forma, no presente estudo a riqueza média encontrada (8,93 espécies) é condizente com o proposto por Matthews (1998), sendo que os pontos G4, G6 e G7 apresentaram riqueza acumulada superior a vinte espécies, e maior taxa de turnover na composição de espécies, demonstrando elevada diversidade $\beta$, que conduziu ao elevado número acumulado de espécies. Quanto à correlação entre taxa de alteração na composição de espécies (turnover), a maior influência do volume dos riachos e da altitude já foi constatada por outros autores para riachos de regiões temperadas (Taylor \& Warren, 2001) e tropicais (Súarez, 2008b), sendo atribuída à maior facilidade de colonização que aumenta a dinâmica da migração em riachos das porções inferiores das bacias.

A despeito de diferenças na amostragem entre os estudos, os trabalhos de Castro et al. (2003, 2004 e 2005) utilizaram pesca elétrica, enquanto no trabalho de Súarez \& Petrere-Júnior (2005) foram utilizadas peneiras e redes de espera, de forma similar ao utilizado no presente estudo. Assim, sugere-se que a diferença observada na riqueza de espécies entre os riachos aqui amostrados e os riachos da bacia do rio Iguatemi encontrada por Súarez \& Petrere-Júnior (2005) possam ser resultado da degradação ambiental constatada por aqueles autores naquela bacia.

A predominância das espécies $B$. stramineus, $A$. paranae e $H$. ancistroides nos riachos amostrados pode ser considerado resultado da ampla distribuição geográfica destas espécies em toda a bacia do Alto Rio Paraná, sendo que $B$. stramineus é uma das espécies mais comuns e abundantes nas assembléias de peixes (Castro et al. 2003, 2004, 2005, Súarez \& Petre Júnior 2005, Valério et al. 2007, Ferreira 2007, Perez-Júnior \& Caravello 2007, Shibatta et al. 2007, Fialho et al. 2008), corroborando um dos princípios do neutralismo nas comunidades biológicas, que sugere que a abundância e ocorrência das espécies nas comunidades locais deva ser resultado principalmente dos padrões regionais de abundância. Desta forma, espécies com maior abundância devem apresentar distribuição ampla em sua área de ocorrência. Assim, apesar de termos analisado no presente trabalho apenas a ocorrência das espécies, a abundância total dessa espécie em todo o período amostrado (960 indivíduos) corrobora os princípios do neutralismo para as comunidades de peixes nos riachos analisados.

Nos riachos por nós amostrados, observa-se claramente a maior influência espacial em detrimento de variações temporais sobre a composição de espécies, visualizada na análise de agrupamento e no resultado da ANOSIM, no qual é possível observar claramente que o ponto G7 é o que mais se isola dos demais, formando um grupo bem diferenciado na análise de agrupamento. Da mesma forma a variação na riqueza de espécies entre locais e a ausência de variação temporal é demonstrada pelos resultados das ANOVAs e pela árvore de regressão. No caso da árvore de regressão a primeira separação entre amostras isola o ponto G7 dos demais. Este ponto era o único localizado em uma planície de inundação da bacia do rio Guiraí. Este fato justifica a sua diferenciação também quanto à composição de

Tabela 3. Resultado da análise de correspondência canônica (CCA) para as comunidades de peixes e os descritores ambientais dos riachos amostrados na bacia do rio Guiraí, Alto Rio Paraná. ns = não significativa; * significativa a $\alpha=0,05 ; * * *=$ significativa a $\alpha=0,001$

Table 3. Results of canonical correspondence analysis (CCA) for fish communities and environmental descriptors of the sampled streams in Guiraí River basin, Upper Paraná basin. ns $=$ non significant; * significant to $\alpha=0.05 ; * * *=$ significant to $\alpha=0.001$.

\begin{tabular}{|c|c|c|c|}
\hline Descritores ambientais & Eixo 1 & Eixo 2 & $\mathbf{r}^{2}$ \\
\hline Largura do riacho & $-0,32$ & 0,87 & $0,74 * * *$ \\
\hline Profundidade do riacho & $-0,80$ & 0,41 & $0,69 * * *$ \\
\hline Velocidade da água & 0,42 & 0,05 & $0,15^{*}$ \\
\hline Altitude & 0,53 & $-0,80$ & $0,81 * * *$ \\
\hline $\mathrm{pH}$ & $-0,06$ & $-0,11$ & $0,01 \mathrm{~ns}$ \\
\hline Condutividade elétrica da água & 0,17 & 0,09 & $0,03 \mathrm{~ns}$ \\
\hline Turbidez da água & 0,09 & 0,20 & $0,04 \mathrm{~ns}$ \\
\hline Temperatura da água & 0,01 & 0,32 & $0,08 \mathrm{~ns}$ \\
\hline Resumo estatístico para os primeiros eixos & - & - & - \\
\hline Variação explicada & 12,1 & 11,2 & - \\
\hline
\end{tabular}




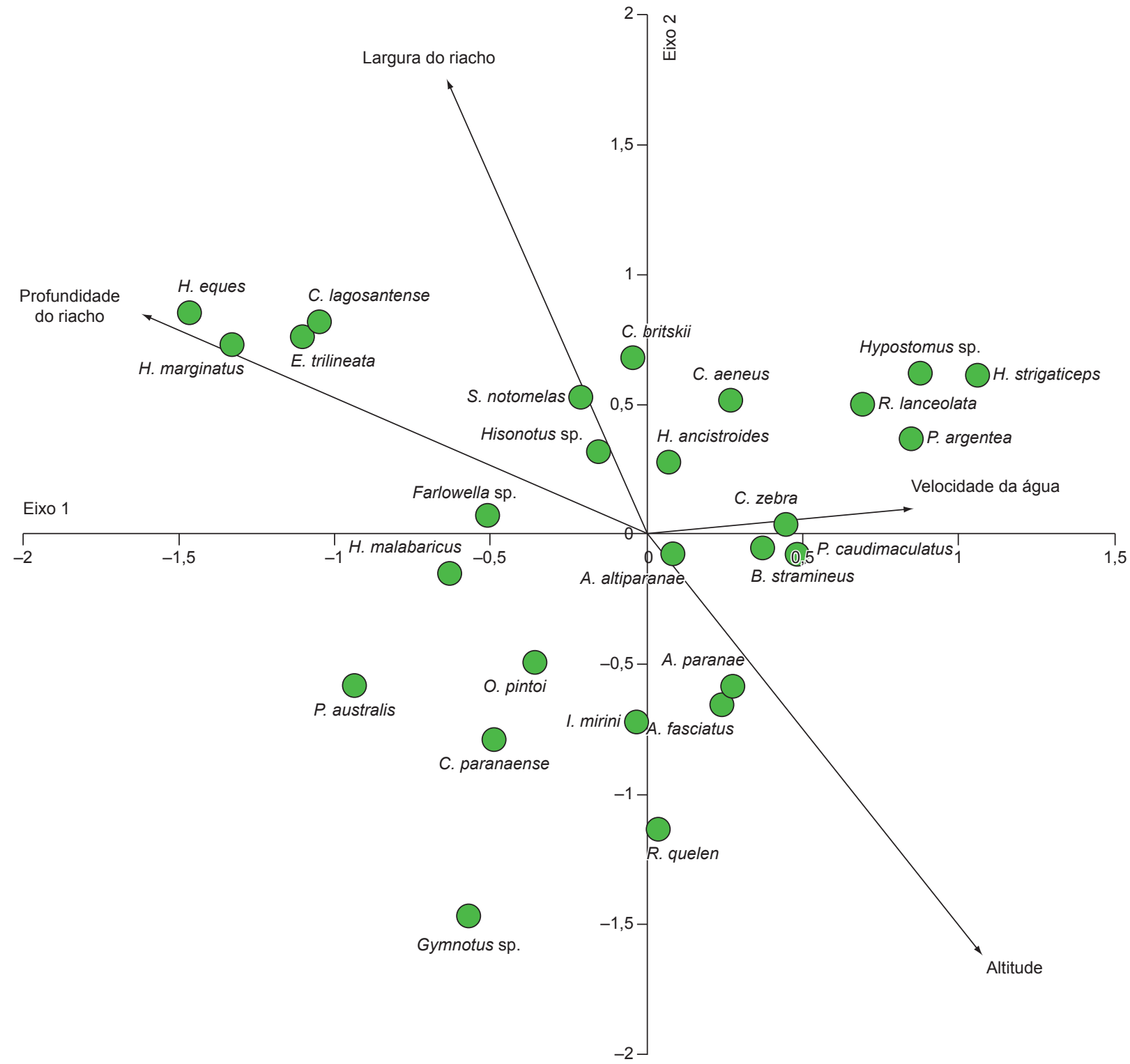

Figura 7. Gráfico de ordenação da análise de correspondência canônica entre as espécies de peixes mais comuns e as características ambientais dos riachos da bacia do rio Guiraí, Alto Rio Paraná.

Figure 7. Scatterplot of Canonical Correspondence Analysis between the main fish species and streams descriptors in Guiraí River basin, Upper Paraná River.

espécies, uma vez que muitas espécies não ocorrem nos trechos de maior altitude e maior velocidade da correnteza. $\mathrm{O}$ aparecimento de algumas espécies de grande porte e em avançado estádio de maturação gonadal nas amostragens do período chuvoso sugere que este local possa ser utilizado como rota na migração reprodutiva e, associado ao fato de várias delas terem apresentado juvenis nas amostragens, indica sua importância também como local de desenvolvimento inicial das espécies de grande porte. Contudo, apenas análises detalhadas da dinâmica reprodutiva das espécies encontradas poderão permitir entender a importância deste local como berçário destas espécies.

A influência positiva da velocidade da correnteza sobre a riqueza de espécies na segunda separação de amostras pela árvore de regressão sugere que, excluindo o G7, os demais riachos se separam pela velocidade da correnteza, sendo que riachos que não são de planície e apresentam velocidade elevada apresentam maior riqueza de espécies.
O grupo com maior riqueza média de espécies na segunda divisão da árvore foi composto por cinco amostras, representando 3 locais (G3, G4 e G6). Os locais G4 e G6 apresentaram duas amostras cada nos meses de outubro, dezembro e fevereiro, sugerindo que esta maior riqueza possa ser resultado de migrações reprodutivas que estariam acrescendo espécies à lista de espécies residentes, demonstrando também um efeito sazonal secundário sobre a riqueza de espécies nos locais amostrados.

Os pontos G4 e G6, além de estarem entre os que apresentam maior velocidade média da água, separando-se claramente dos pontos G1, G2 e G7, estão entre os que apresentam maior largura (4,37 e $3,43 \mathrm{~m}$, respectivamente). Desta forma, a maior riqueza de espécies no período chuvoso constatada nestes locais sugere que estes locais possam ser mais influenciados por migrações de algumas espécies de peixes (Figura 4). O ponto G6, apesar da elevada velocidade da 
corrente, encontra-se no trecho inferior da bacia, o que provavelmente explica neste local a ocorrência de várias espécies comuns na planície de inundação (p. ex.; H. marginatus e $M$. sanctaefilomenae), além de $S$. notomelas que, apesar de ser amplamente distribuída, apresenta preferência por locais com menor velocidade da correnteza (Súarez et al. 2007). Desta forma a riqueza de espécies no ponto G6 foi, em algumas amostragens (período chuvoso), incrementada pela presença destas espécies. Assim, constata-se que ocorre a interação de fatores em escala regional (altitude), associadas aos fatores locais (profundidade, velocidade e largura) dos riachos definindo a composição de espécies em cada um dos riachos amostrados, resultado que fica mais claro na análise de correspondência canônica.

A maior importância da variação espacial quando comparada à temporal já tem sido constatada por outros estudos para riachos do Alto Rio Paraná (Langeani et al. 2005, Cetra \& Petrere Júnior 2006, Valério et al. 2007, Súarez \& Petrere Júnior 2007). Analisando as comunidades de peixes de corredeiras e remansos na bacia do Alto Rio Paraná, Langeani et al. (2005) sugerem que muitas espécies apresentam ampla distribuição sazonal e nos habitats analisados, sendo pouco influenciadas pelas variações sazonais; contudo, algumas espécies tendem a ocorrer somente no período de chuvas, como resultado da migração reprodutiva. Por outro lado, os mesmos autores encontraram clara diferenciação entre comunidades de corredeiras e remansos.

A teoria do rio contínuo sugere que ocorram alterações previsíveis nas comunidades aquáticas de acordo com a sua posição na rede de drenagem, uma vez que as comunidades de trechos de cabeceira devem apresentam menor riqueza de espécies e maior dependência da vegetação ripária quando comparada aos trechos finais. Estas hipóteses têm sido constantemente validadas em diferentes regiões (Robinson \& Rand 2005, Súarez \& Petrere Júnior 2007), sendo que as diferenças na habilidade de colonização das espécies nos trechos mais elevados e com características hidrológicas mais severas tem sido comumente utilizada para explicar a zonação longitudinal (Súarez et al. 2007).

Ainda que os riachos por nós coletados incluam trechos de cabeceira e trecho final da bacia do rio Guiraí, os trechos de nascente encontram-se em altitudes relativamente baixas. Esta baixa altitude, por um lado reforça as conclusões dos demais autores; onde mesmo com menor variação altimétrica, as variáveis associadas à colonização dos riachos (altitude, largura, velocidade e profundidade dos riachos) assumem o papel principal na definição da riqueza e composição local de espécies, contudo sem problemas de vícios amostrais (p. ex.: somente riachos estreitos, rasos e correntosos nas cabeceiras e riachos volumosos e com baixa velocidade na planície). Por outro lado, esta menor variação altimétrica, associada à ocorrência de locais com elevada velocidade da correnteza mesmo em baixas altitudes (G6), levou à diferenciação espacial, principalmente entre o ponto G7 e os demais. Isso demonstra que apesar da baixa velocidade da correnteza, as demais características hidrológicas (altitude, largura, velocidade) do ponto G1 limitam a sua colonização por espécies típicas de planície de inundação.

Palmer \& Poff (1997), discutindo o efeito da heterogeneidade espacial e temporal sobre os padrões e processos em riachos, sugerem que a heterogeneidade observada nos riachos é de fundamental importância para a dinâmica da interação predador-presa, interferindo diretamente na eficiência dos predadores e sobreposição de nichos. Desta forma, a diferenciação na riqueza e composição de espécies entre os trechos superiores (G1 a G5) e inferiores da bacia (G6 e G7), influenciadas pelas características hidrológicas como limitantes da distribuição dos peixes (Bain et al. 1988, Poff 1997, Gerhard et al. 2004, Súarez et al. 2007), pode permitir o incremento da riqueza em nível regional (bacia hidrográfica) através da diminuição da sobre- posição de nichos e assim permitindo a manutenção de subconjuntos populacionais (para as espécies de distribuição ampla), que podem resistir melhor às alterações antrópicas. Cabe ressaltar que a ocorrência de T. rendalli, espécie exótica proveniente de pisciculturas da região, sugere que as comunidades de peixes da bacia do rio Guiraí podem estar apresentando diferenças na sua estrutura em função da interferência antrópica. Isto reforça a necessidade de elaboração de medidas de manejo que procurem garantir a integridade das comunidades aquáticas na região, contribuindo com ações já tomadas na região, como a implantação do Parque Estadual das Várzeas do rio Ivinhema, na qual o rio Guiraí atua como limite norte.

\section{Agradecimentos}

À Fundect (Processo n 41/100.143/2006) pelo financiamento do projeto e à prefeitura municipal de Novo Horizonte do Sul pelo apoio logístico às atividades de campo. A João Paulo da Silva, Lílian P. Vasconcelos, Lucas Brandão Gonçalves, Marcelo Maldonado de Souza, Sabrina B. Valério, Suelen Ap. de Oliveira e Viviane V. Azevedo pelo auxílio nos trabalhos de campo.

\section{Referências Bibliográficas}

ABES, S.S. \& AGOSTINHO, A.A. 2001. Spatial patterns in fish distributions and structure of the ichthyocenosis in the Água Nanci stream, upper Paraná River basin, Brazil. Hydrobiol. 445(1-3):217-227.

AGOSTINHO, A.A., GOMES, L.C., VERÍSSIMO, S. \& OKADA, E.K. 2004. Flood regime, dam regulation and fish in the Upper Paraná River: effects on assemblage attributes, reproduction and recruitment. Rev. Fish Biol. Fisher. 14(1):11-19.

BAIN, M.B., FINN, J.T. \& BOOKE, H.E. 1988. Streamflow regulation and fish structure. Ecology, 69(2):382-392.

BRITSKI, H.A., SILIMON, K.Z. \& LOPES B.S. 1999. Peixes do Pantanal: manual de identificação. Embrapa-SPI; Embrapa-CPAP, Brasília; Corumbá.

CASTRO, R.M.C., CASATTI, L., SANTOS, H.F., FERREIRA, K.M., RIBEIRO, A.C., BENINE, R.C., DARDIS, G.Z.P., MELO, A.L.A., ABREU, T.X., BOCKMANN, F.A., CARVALHO, M., GIBRAN, F.Z. \& LIMA, F.C.T. 2003. Estrutura e composição da ictiofauna de riachos do Rio Paranapanema, sudeste e sul do Brasil. Biota Neotrop. 3(1): http:// www.biotaneotropica.org.br/v3n1/pt/abstract?article+BN01703012003 (último acesso em 12/12/2007).

CASTRO, R.M.C., CASATTI, L., SANTOS, H.F., MELO, A.L.A., MARTINS, L.S.F., FERREIRA, K.M., GIBRAN, F.Z., BENINE, R.C., CARVALHO, M., RIBEIRO, A.C., ABREU, T.X., BOCKMANN, F.A., DARDIS, G.Z.P., STOPIGLIA, R. \& LANGEANI, F. 2004. Estrutura e composição da ictiofauna de riachos da bacia do Rio Grande, no Estado de São Paulo, Sudeste do Brasil. Biota Neotrop. 4(1): http://www.biotaneotropica. org.br/v4n1/pt/abstract?article+BN0170402004 (último acesso em $13 / 12 / 2007)$.

CASTRO, R.M.C., CASATTI, L., SANTOS, H.F., VARI, R.P., MELO, A.L.A., MARTINS, L.S.F., ABREU, T.X., BENINE, R.C., GIBRAN, F.Z., RIBEIRO, A.C., BOCKMANN, F.A., CARVALHO, M., PELIÇÃO, G.Z., FERREIRA, K.M., STOPIGLIA, R. \& AKAMA, A. 2005. Structure and composition of the stream ichthyofauna of four tributary rivers of the upper Rio Paraná basin, Brazil. Ichthyol. Explor. Freshwaters, 16(3):193-214.

CETRA, M. \& PETRERE Jr., M. 2006. Fish assemblage structure of the Corumbataí River Basin, São Paulo State, Brazil: characterization and anthropogenic disturbances. Braz. J. Biol. 66(2A):431-439.

CLARKE, K.R. 1993. Non-parametric multivariate analysis of changes in community structure. Aust. J. Ecol. 18(1):117-143.

COLWELL, R.K. 1997. Estimates 5: statistical estimation of species richness and shared species from samples. University of Connecticut, Storrs. Version 5.0.1 (viceroy.eeb.uconn.edu/estimates, 08.ix.2001). 
DE'ATH, G. \& FABRICIUS, K.E. 2000. Classification and regression trees: a powerful yet simple technique for ecological data analysis. Ecology, 81(11):3178-3192.

EFRON, B. 1979. Bootstrap methods: another look at the jackknife. Ann. Stat., 7(1):1-26.

FERREIRA, C.P. \& CASATTI, L. 2006. Influência da estrutura do habitat sobre a ictiofauna de um riacho em uma micro-bacia de pastagem, São Paulo, Brasil. Revta. Bras. Zool. 23(3):642-651.

FERREIRA, K.M. 2007. Biology and ecomorphology of stream fishes from the Mogi-Guaçu basin, Southeastern Brazil. Neotrop. Ichthyol. 5(3):311-326.

FIALHO, A.P., OLIVEIRA, L.G., TEJERINA-GARRO, F.L. \& MÉRONA, B. 2008. Fish-habitat relationship in a tropical river under anthropogenic influences. Hydrobiol. 598(1):315-324.

GERHARD, P., MORAES, R. \& MOLANDER, S. 2004. Stream fish communities and their associations to habitat variables in a rain forest reserve in southeastern Brazil. Environ. Biol. Fishes, 71(4):321-340.

GRAÇA, W.J. \& PAVANELLI, C.S. 2007. Peixes da planície de inundação do alto rio Paraná e áreas adjacentes. EDUEM, Maringá.

HOEINGHAUS, D.J., WINEMILLER, K.O. \& BIRNBAUM, J.S. 2007. Local and regional determinants of stream fish assemblage structure: inferences based on taxonomic vs. functional groups. J. Biogeogr. 34(2):324-338.

JACKSON, D.A., PERES-NETO, P.R. \& OLDEN, J.D. 2001. What controls who is where in freshwater fish assemblages: the roles of biotic, abiotic, and spatial factors. Can. J. Fish. Aquat. Sci. 58(1):157-170.

JONGMAN, R.H.G., TER BRAAK, C.J.F. \& VAN TONGEREN, O.F.R. 1995. Data analysis in community and landscape ecology. Cambridge Univ. Press, Cambridge.

LANGEANI, F., CASATTI, L., GAMEIRO, H.S., CARMO, A.B. \& ROSSAFERES, D.C. 2005. Riffle and pool fish communities in a large stream of southeastern Brazil. Neotrop. Ichthyol. 3(2):305-311.

LANGEANI, F., CASTRO, R.M.C., OYAKAWA, O.T., SHIBATTA, O.A., PAVANELLI, C.S \& CASATTI, L. 2007. Diversidade da ictiofauna do alto rio Paraná: composição atual e perspectivas futuras. Biota Neotrop. 7(3): http://www.biotaneotropica.org.br/v7n3/pt/ abstract?article+bn03407032007 (último acesso em 13/12/2007).

LÉVÊQUE, C., OBERDORFF, T., PAUGY, D., STIASSNY, M.L.J. \& TEDESCO, P.A. 2008. Global diversity of fish (Pisces) in freshwater. Hydrobiologia, 595(1):545-567.

MATTHEWS, W.J. 1998. Patterns in freshwater fish ecology. Chapman \& Hall, New York.

OKSANEN, J., KINDT, R., LEGENDRE, P. \& O'HARA, B. 2006. Community ecology package: vegan. Oulu. Version. 1.8.1. Disponível em: http://cc.oulu.fi/ jarioksa/ (último acesso em 15/09/2007).

PALMER, M.A. \& POFF, N.L. 1997. The influence of environmental heterogeneity on patterns and process in streams. J. N. Am. Benthol. Soc. 16(1):169-173.

PAVANELLI, C.S. \& CARAMASCHI, E.P. 2003. Temporal and spatial distribution of the ichthyofauna in two streams of the upper Rio Paraná Basin. Braz. Arch. Biol. Technol. 46(2):271-280.

PERES-NETO, P.R. 2004. Patterns in the co-occurrence of fish species in streams: the role of site suitability, morphology and phylogeny versus species interactions. Oecologia, 140(2):352-360.
PEREZ Jr., O.R. \& GARAVELLO, J.C. 2007. Ictiofauna do ribeirão do Pântano, afluente do rio Mogi-Guaçu, bacia do alto rio Paraná, São Paulo, Brasil. Iheringia, Zool. 97(3):328-335.

POFF, N.L. 1997. Landscape filters and species traits: towards mechanistic understanding and prediction in stream ecology. J. N. Am. Benthol. Soc. 16(2):391-409.

R DEVELOPMENT CORE TEAM. 2005. R: a language and environment for statistical computing. R Foundation for Statistical Computing, Vienna.

REIS, R.E., KULLANDER, S.O. \& FERRARIS, Jr., C.J. 2003. Check list of the freshwater fishes of South and Central America. EDIPUCRS, Porto Alegre.

ROBINSON, J.L. \& RAND, P.S. 2005. Discontinuity in fish assemblages across an elevation gradient in a southern Appalachian watershed, USA. Ecol. Freshw. Fish, 14(1):14-23.

SHIBATTA, O.A., GEALH, A.M. \& BENNEMANN, S.T. 2007. Ictiofauna dos trechos alto e médio da bacia do rio Tibagi, Paraná, Brasil. Biota Neotrop. 7(2): http://www.biotaneotropica.org.br/v7n2/pt/ abstract?article+bn02107022007 (último acesso em 13/01/2008)

SÚAREZ, Y.R. 2008a. Fish, lower Ivinhema river basin streams, state of Mato Grosso do Sul, Brazil. Check List, 4(3):226-231.

SÚAREZ, Y.R. 2008b. Variação espacial e temporal na diversidade e composição de espécies de peixes em riachos da bacia do rio Ivinhema, Alto Rio Paraná. Biota Neotrop. 8(3): http://www.biotaneotropica. org.br/v8n3/en/abstract?article+bn02308032008 (último acesso em $19 / 10 / 2008)$

SÚAREZ, Y.R., VALÉRIO, S.B., TONDATO, K.K., XIMENES, L.Q.L. \& FELIPE, T.R.A. 2007. Determinantes ambientais da ocorrência de espécies de peixes em riachos de cabeceira da bacia do rio Ivinhema, Alto Rio Paraná. Acta Sci., Biol. Sci. 19(2):145-150.

SÚAREZ, Y.R. \& PETRERE Jr., M. 2007. Environmental factors predicting fish communities structure of two neotropical rivers in Brazil. Neotrop. Ichthyol. 5(1):61-68.

SÚAREZ, Y.R. \& PETRERE Jr., M. 2005. Organização das assembléias de peixes em riachos da bacia do rio Iguatemi, Mato Grosso do Sul. Acta Sci., Biol. Sci. 22(2):161-167.

TAYLOR, C.M. \& WARREN Jr., M.L. 2001. Dynamics in species composition of stream fish assemblages: environmental variability and nested subsets. Ecology, 82(8):2320-2330.

TER BRAAK, C.J.F. 1986. Canonical correspondence analysis: a new eigenvector technique for multivariate direct gradient analysis. Ecology, 67(5):1167-1179.

TURGEON, K. \& RODRÍGUEZ, M.A. 2005. Predicting microhabitat selection in juvenile Atlantic salmon Salmo solar by the use of logistic regression and classification trees. Freshwater Biol. 50(4):539-551.

VALÉRIO, S.B., SÚAREZ, Y.R., FELIPE, T.R.A., TONDATO, K.K. \& XIMENES, L.Q.L. 2007. Organization patterns of headwater-stream fish communities in the Upper Paraguay-Paraná basins. Hydrobiol. 583(1):241-250. 
